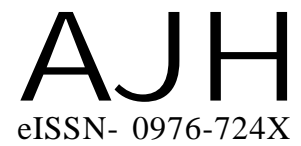

THEASIAN JOURNALOF HORTICULTURE

Volume 11 | Issue 1 | June, 2016 | 224-232

Visit us -www.researchjournal.co.in
Article history :

Received : 18.03 .2016

Accepted : 27.05.2016

\footnotetext{
Members of the Research Forum

Associated Authors:

${ }^{1}$ Department of Pomology and

Floriculture, College of

Horticulture, Kerala Agricultural

University, Vellanikkara, THRISSUR

(KERALA) INDIA

Email : lilamathew@yahoo.com;

ajithkumar.k@kau.in

Author for correspondence :

A. ASWINI

Department of Pomology and

Floriculture, College of Agriculture,

Kerala Agricultural University,

Vellayani, THIRUVANANTHAPURAM

(KERALA) INDIA

Email : aswini.ajith@gmail.com
}

\title{
Potentialities of antioxidants in fruit crops
}

\section{A. ASWINI, LILA MATHEW ${ }^{1}$ AND K. AJITHKUMAR ${ }^{1}$}

KEY WORDS : Antioxidants, Fruit crops, Reactive oxygen species, Antioxidants

HOW TO CITE THIS ARTICLE : Aswini, A., Mathew, Lila and Ajithkumar, K. (2016). Potentialities of antioxidants in fruit crops. Asian J. Hort., 11(1) : 224-232, DOI : 10.15740/HAS/TAJH/11.1/224-232.
$\mathrm{T}$ The doctrine 'Let food be thy medicine' espoused by Hippocrates nearly 2500 years ago is receiving interest by the researchers now a days. Recently, the focus has been shifted to the achievement of a balanced diet, and maximization of both life expectancy and quality, by identifying food ingredients that improve the capacity to resist disease and enhance health (Agte and Tarwadi, 2012). There has been a rapid increase in the oxidative stress and associated disorders such as prevalence of diabetes, cataract and cardiovascular diseases, due to the rapid changes in diet and lifestyle. The natural strategies such as increased intake of antioxidant rich food could be a valuable tool in coping up with the stress.Fruits form an integral part of our daily balanced diet ensuring abundant supply of antioxidants which prevents the risk of many chronic diseases (FAO, 2004). Important antioxidants in fruits include polyphenols, ascorbic acid, $\beta$ carotene and vitamin E (Mitra et al., 2014). Antioxidants are the compound that are capable of quenching or stabilizing free radicals and plays an important role in the body defense system.

\section{Reactive oxygen species (ROS) :}

ROS represents a broad category of molecules that indicate the collection of radical and non radical oxygen derivatives.Non radicals have no unpaired electron and are generation from free radical species. There intermediates may participate in reactions that give rise to free radicals that damage organic substrate.In addition, there is another class of free radicals that are nitrogen derived called reactive nitrogen species (RNS). They are nitrogen derived molecules and are considered a subclass of ROS.

\section{Sources of ROS production :}

A number of sources of ROS were recognized in physiological and pathological conditions. Some of the widely accepted sources of ROS are classified in to exogenous and endogenous sources.Exogenous sources include; electromagnetic radiation, cosmic radiation, car exhaust, UV light, cigarette smoke, ozone and low wave length electromagnetic radiation.Endogenous sources include; electron leakage during metabolic processes, NADPH oxidase (leukocytes and macrophages), 